\title{
Correction to: Integrated GP care for patients with persistent physical symptoms: feasibility cluster randomised trial
}

Meenal Patel ${ }^{1 \dagger}$, Kirsty James ${ }^{2 \dagger}$, Rona Moss-Morris ${ }^{3}$, Mark Ashworth ${ }^{4}$, Mujtaba Husain ${ }^{5}$, Matthew Hotopf ${ }^{1,5}$, Anthony S. David ${ }^{6}$, Paul McCrone ${ }^{7}$, Sabine Landau ${ }^{2+}$, Trudie Chalder ${ }^{1 *+}$ (D) and on behalf of the PRINCE Primary trial team

\section{Correction to: BMC Fam Pract 21, 207 (2020) https://doi.org/10.1186/s12875-020-01269-9}

Following publication of the original article [1], an error which was reported in the title was corrected:

From: BMC family practice integrated GP care for patients with persistent physical symptoms: feasibility cluster randomised trial

To: Integrated GP care for patients with persistent physical symptoms: feasibility cluster randomised trial
Published online: 06 November 2020

\section{Reference}

1. Patel M, James K, Moss-Morris R, et al. BMC family practice integrated GP care for patients with persistent physical symptoms: feasibility cluster randomised trial. BMC Fam Pract. 2020;21:207. https://doi.org/10.1186/ s12875-020-01269-9.

\begin{abstract}
Author details
'Department of Psychological Medicine, Institute of Psychiatry, Psychology and Neuroscience, King's College London, 16 De Crespigny Park, London SE5 8AF, UK. ${ }^{2}$ Department of Biostatistics and Health Informatics, Institute of Psychiatry, Psychology and Neurosciences, Psychology and Neuroscience King's College, London, UK. ${ }^{3}$ Psychology Department, Institute of Psychiatry, Psychology and Neuroscience, King's College, London, UK. ${ }^{4}$ School of Population Health and Environmental Sciences, Faculty of Life Sciences and Medicine King's College London, London, UK. ${ }^{5}$ UK South London and Maudsley NHS Foundation Trust, London, UK. ${ }^{6}$ Division of Psychiatry, Maple House, UCL Institute of Mental Health, 149 Tottenham Court Road, London W1T 7NF, UK. 'Institute for Lifecourse Development, University of Greenwich, Old Royal Naval College, Park Row, Greenwich, London SE10 9LS, UK.
\end{abstract}

The original article can be found online at https://doi.org/10.1186/s12875020-01269-9.

* Correspondence: trudie.chalder@kcl.ac.uk

${ }^{\dagger}$ Meenal Patel and Kirsty James joint first authors

'Sabine Landau and Trudie Chalder joint last authors

1 Department of Psychological Medicine, Institute of Psychiatry, Psychology and Neuroscience, King's College London, 16 De Crespigny Park, London SE5 $8 \mathrm{AF}, \mathrm{UK}$
() The Author(s). 2020 Open Access This article is licensed under a Creative Commons Attribution 4.0 International License, which permits use, sharing, adaptation, distribution and reproduction in any medium or format, as long as you give appropriate credit to the original author(s) and the source, provide a link to the Creative Commons licence, and indicate if changes were made. The images or other third party material in this article are included in the article's Creative Commons licence, unless indicated otherwise in a credit line to the material. If material is not included in the article's Creative Commons licence and your intended use is not permitted by statutory regulation or exceeds the permitted use, you will need to obtain permission directly from the copyright holder. To view a copy of this licence, visit http://creativecommons.org/licenses/by/4.0/ The Creative Commons Public Domain Dedication waiver (http://creativecommons.org/publicdomain/zero/1.0/) applies to the data made available in this article, unless otherwise stated in a credit line to the data. 